This is the Accepted Author Manuscript of a chapter published as Katalin Orbán, Hierarchies of Pain: Trauma

Tropes Today and Tomorrow. In: Dominic Davies and Candida Rifkind (eds.), Documenting Trauma in Comics:

Traumatic Pasts, Embodied Histories, and Graphic Reportage. London: Palgrave Macmillan, 29-48 (2020)

(Palgrave Studies in Comics and Graphic Novels ). DOI:10.1007/978-3-030-37998-8_2

\title{
Hierarchies of Pain: Trauma Tropes Today and Tomorrow
}

\section{Katalin Orbán}

\begin{abstract}
Trauma has become a pervasive cultural model for representing individual and collective injuries and suffering. This process has produced what may be called a trauma aesthetic, a set of recognizable tropes in widespread use in trauma narratives. This chapter examines the adoption of this aesthetic in graphic narratives, focusing on the special capacities of the form. Familiar tropes, such as dissociation and the somatic trace, are presented in complex combinations of visual and textual components, often exploiting the differential appearance of text and image to introduce a dynamic of belatedness or disarticulation. The chapter analyzes five works ordered according to their diminishing reliance on 'trauma'. The trauma aesthetic is used, though not explicitly, in Catherine Meurisse's La Légèreté (2016) about the Charlie Hebdo attack, Jean-Philip Stassen's Deogratias (2000/2006) about the genocide in Rwanda, and Emmanuel Lepage's Un printemps à Tchernobyl (2012) about the aftermath of the Chernobyl nuclear disaster. By contrast, it is absent from Mazen Kerbaj's Beirut Won't Cry (2007/2017) about the Israel-Hezbollah conflict and Josh Neufeld's A.D. about Hurricane Katrina (2009). These works' reliance on formalized and sanctioned trauma tropes is not only influenced by narrative characteristics, such as temporal distance from the event or the presence of a single narrator-protagonist, but may also be motivated by the prestige conferred by trauma as recognized suffering, affecting the canonization and translatability of the graphic narratives in question.
\end{abstract}

\section{Introduction: Trauma Aesthetics and Recognition}

The rise of trauma as a prominent cultural discourse for the representation of individual and collective injuries and catastrophic events in the twentieth century has transformed trauma from a specialized medical and psychoanalytical term into a household concept that permeates our culture. This has also produced what we might call a trauma aesthetic, certain tropes that are in widespread use in literary trauma narratives: negative tropes of disconnection and unavailability (the putative quasi-sacred inexpressibility of trauma and its unavailability to human understanding) and positive tropes of return (the uncontrollable return of an intact experience of overwhelming sensory impressions). Over the past decades 'trauma' has been drifting away from 'single, unexpected, often life-threatening' events (McNally, 2003: 173), 
to more diffuse or less acute threats, and to repeated, predictable suffering. Most recently, it has shifted from trauma as direct exposure to an increasingly fluid boundary between actual and virtual trauma envisioned particularly in the wake of the televisual spectacle of 9/11.

Yet it is curious that the continuous expansion and attenuation of 'trauma' during these decades has, arguably, not been accompanied by a corresponding diversification of the trauma genre, whether in its conceptualization, tropes, or geopolitical relevance; in fact, the opposite is the case. Trauma now functions as a very narrow framework with pronounced geopolitical emphases and increasingly codified elements that help integrate a work into a canon of trauma narratives. This codification began with testimonial accounts and literary narratives, but it has been transferred to other genres, including long-form graphic narratives, relying on both established conventions of a trauma aesthetic and the distinctive capacities of the medium. In this chapter, I will examine Catherine Meurisse's La Légèreté (2016) as a work that creatively and comprehensively adopts this increasingly codified trauma aesthetic to the comics form. I then draw on several twenty-first-century graphic narratives, both fictional and documentary, that are concerned with public historical trauma as it affects private lives, and which rely on this specific trauma aesthetic to a lesser degree or eschew it altogether. $^{1}$

Alan Gibbs has recently argued in reference to contemporary American literature that elements of trauma theory have been reified into an 'often prescriptive aesthetic', so that '[e]lements of representation that were once highly experimental have become instead aesthetic tropes of the "trauma genre"" (Gibbs, 2014: 148). These aesthetic tropes correspond to a specific view of trauma that fosters particular expectations, such as absence and inexpressibility, and the production and reception of trauma narratives have become mutually reinforcing in this respect. Gibbs' remarks on this consolidated literary trauma aesthetic focused on works written in response to $9 / 11$, but I would argue that the consolidation of trauma culture and a trauma aesthetic was already so well developed that, by the mid-1990s, a highly successful fake or delusional Holocaust memoir could be produced and received as an 'authentic' trauma narrative. This real-world litmus test for the recognizability of the 'trauma genre' was the famous and extensively researched 1995 case of Binjamin Wilkomirski's Bruchstücke (Fragments), a fake Holocaust memoir that was acclaimed as a uniquely

\footnotetext{
${ }^{1}$ While narratives of personal trauma (such as illness, accident, violence, death, abuse, etc.) also merit analysis in this context - and can in fact raise productive questions about the relative canonization and codification of public historical trauma narratives and personal trauma narratives - this is beyond the scope of the present study.
} 
powerful testimonial work for three years until its exposure as fraudulent. ${ }^{2}$ The specific repertoire of cultural signals deployed and recognized in Wilkomisrki's trauma narrative included the emphasis on seeing as disconnected from understanding, the disconnection between the trauma and the present, and the uncontrollable pull of an unbearable past contained in a necessarily fragmented anti-narrative. The text epitomized this already recognizable, though not yet codified, trauma aesthetic by privileging extreme narrative difficulty and narrative reflections of diverse dissociative symptoms: 'derealization, a strange dreamlike sense that one's surroundings are unreal; depersonalization, a sense of being disconnected from one's body; a sense that time is either slowing down or speeding up; and amnesia, an inability to recall important aspects of what happened' (McNally, 2003: 172)often inevitably eclipsing socio-historical context. This focus on disconnection corresponds to an emphasis on inaccessibility and inarticulability informed by the influential doxa of trauma theory as it was evolving in the 1990s, and which is best represented in Cathy Caruth's stark formulation:

the inability fully to witness the event as it occurs, or the ability to witness the event fully only at the cost of witnessing oneself. Central to the very immediacy of this experience, that is, is a gap that carries the force of the event and does so precisely at the expense of simple knowledge and memory. The force of this experience would appear to arise precisely, in other words, in the collapse of its understanding. (Caruth, 1996: 7)

The ambivalent recognition of (a potentially prescriptive) trauma aesthetic as an aesthetic deployable in a range of creative work is captured well in post-exposure responses to Wilkomirski's 'memoir'. When Ruth Klüger, a literary historian and author of a renowned Holocaust memoir, comments that the work instantly deteriorated into kitsch when exposed as fiction (1998), this charge is itself compatible with trauma aesthetics and the particular surface-depth structure attributed to trauma, in which a deeper, hidden truth must always

\footnotetext{
${ }^{2}$ Between 1995 and 1998, Wilkomirski's Bruchstücke (Fragments), a Holocaust memoir of his childhood, was translated into nine languages and received countless favourable reviews internationally and major book awards in the US, England and France. Its author toured widely, appearing before general and university audiences (Maechler, 2001: 114-117). It was exposed as fictional in 1998, when its author was identified as Bruno Doesseker, but Wilkomirski/Doesseker insisted on the authenticity of his memoir. This became known as the Wilkomirski case. See Maechler, 2001; Suleiman, 2000; Vice, 2002.
} 
underwrite the symptoms of the surface. This is what Susannah Radstone identifies as a distinctive epistemology in which 'past experiences of trauma [too terrible to be directly recalled] can, if only with difficulty and to a degree, pass [...] from the hidden to the light', and a corresponding 'critical duty to bear witness to the sufferings of the past' (Radstone, 2010: 17-18). As the trauma genre becomes increasingly familiar, formalized difficulties and gaps weaken as symptoms of hidden suffering, and emerge instead as freely deployed tools in the imaginative creation of recognizable traumatic scenarios.

\section{Imagination Blocked}

A recent work that exemplifies the transfer of this trauma aesthetic to graphic narrative is $L a$ Légèreté (2016), Catherine Meurisse's luminous and darkly witty memoir of the Charlie Hebdo attack and its aftermath. Meurisse's compelling and well-received book employs the discourse of trauma and the standard tropes of the increasingly dominant cultural framework for representing and metaphorizing trauma, foregrounding dissociative symptoms and developing a range of images and metaphors to represent the belated impact of experience. In doing so, the book goes well beyond the natural affinities between trauma aesthetic and the elliptical frame-gutter grammar of the comics form, which is fundamentally complicated, of course, by its investment in the visual (Chute, 2017: 34, 54). It is the significance of gaps and concealment in the panel arrangements as well as the multimodal word-and-image relations that connects comics and trauma in this argument. The succession of what is positively presented in a panel sequence relies on an integral visual absence, the negative space of the gutter between juxtaposed frames. Since words and images have a predominantly nonillustrative and non-redundant relationship in comics, their dynamic relationship is not only collaborative, but also highlights the relative capabilities and limitations of the two modes, thereby accentuating what each fails to reveal. La Légèreté exploits these formal affinities, but also foregrounds the representation of trauma thematically, as the core problem driving the plot.

The difficulties of remembering, reconstructing and telling are so central in the book that they constrict the field of experience to a self-reflexive subjective space of perceptions and misperceptions, almost completely displacing the socio-political context of the event that took place in Paris on January 7, 2015, and left twelve people dead. The larger global context is limited to an ironic visual juxtaposition of 25-year-old Meurisse and the two terrorists (the unnamed Kouachi brothers) simultaneously receiving their work contracts, to be editorial 
cartoonists and editorial cartoonist killers, respectively (Meurisse, 2016: 29). Occasional glimpses of the public context include references to Charlie Hebdo, coverage of the attack and the aftermath in public, the media's relentless pursuit of publishable material, and the saturation of public space with 'Je suis Charlie' signs in stores and at rallies. Except for these sporadic references, the narrative is restricted to a personal landscape of reconstruction, predominantly through the imagined therapeutic effects of art.

Thus the story largely transpires in lacunar subjective spaces of blocked feeling, knowing, and remembering, their bleakness mercifully tempered by barbs of self-irony and black humour. The solitary, private nature of these spaces is pre-figured by an early doublepage spread of blank paintings in a gallery hall (18-19), a muted watercolour sequence rendered in blue and grey tones that directly follows the sequence documenting the attack (1517). Meurisse traverses the blankness of empty gallery halls, a loss of representation corresponding to Meurisse's own imminently announced creative block. The sole visible artwork in the gallery is The Scream (1893) by Edvard Munch, an iconic image of human shock and breakdown (2016: 20). The painting is also a familiar pop culture icon, the subject of countless memes and visual gags, and its visual quotation in a comic book infuses the drama with the darkly comic potential of caricature. As Meurisse's reinterpretation of paintings and sculptures blend smoothly into her own style (Groensteen, 2017: par.9), the comic potential is derived not from remediation itself (as the possible demotion of a prestigious art form), but rather from the whimsical, ironic diminution of character both in the emoji-inspiring icon and in Meurisse's lightly sketched persona. Similarly, when her selfdoubting quest for the healing power of art keeps turning up countless representations of death and mutilation in artworks in Rome, the emphasis is not on the re-drawn images' expressive limitations, but rather on her hypersensitive perception of the potential for violence.

La Légèreté combines its figurations of key elements of trauma aesthetic with explicit references to the discourse of traumatic shock and dissociation. For example, Meurisse's psychiatrist explains her condition in medical terms in seven detailed, free-floating panels: she has been a victim of traumatic shock and her brain responded to a life-threatening situation by going into a state of dissociation, causing 'emotional, sensory and memorial anesthesia' (55). She also receives a prognosis of future re-association-although Meurisse rarely depicts herself drawing the bande dessinée to achieve this reassociation (109), this prognosis is, of course, accomplished in the book we are reading. This scene of medical explanation integrates and reinforces numerous earlier explicit references to blockage, 
numbness, isolation and the inability to access one's own experience: 'I am indifferent. My imagination is blocked'; 'I hear nothing. I feel nothing'; 'I am as hollow as a limpet, damn it'; 'I don't know who I am any more. I am floating in nothingness' $(35,37,52)$. Some of these statements occur during a tragicomic visit to Cabourg, a ludicrously commercialized Proust tourist site, suggested to Meurisse by a friend as a possible cure for her loss of memory and feeling. An extended sequence recounts a hilariously overdetermined experiment of reading from Proust at the salon of the Grand Hotel in Cabourg over the 'Marcel Proust special' of tea and cakes. The protagonist's traumatic symptoms contrast starkly with the invasion of memory and feeling as they are recited in the famous madeleine passage of Swann's Way. Meurisse's hollowness, which is compared to a limpet on the Cabourg beach, is the counterpart to the cakes that look 'as though they have been molded in the grooved valve of a scallop shell' (Proust, 2003: 45). The passage invokes the epistemology of trauma with its structure of an intact, essential testimonial truth of past experience, one that is deposited inside its carrier (Meurisse herself), yet which remains inaccessible to her.

Crucially for a transfer of a trauma aesthetic to graphic narrative, La Légèreté employs distinctive multimodal strategies for emphasizing inaccessibility, dissociative states, and the impossibility or difficulty of articulation. First, it visualizes inaccessibility and engulfment, by using visual signs and metaphors of blockage, post-traumatic states, and subjective landscapes of isolation and engulfment. These analogical representations of subjective experience take full advantage of drawing and painting as embodied, non-photographic practices. Early trauma theory has been critiqued for its use of undue metaphorization and the conflation of traumatic experiences with quasi-traumatic ones (LaCapra, 2000; Kansteiner, 2006; Craps, 2014), yet these visual metaphors complicate their illustrative, metaphorical functions due to the nature of the comics form, in which images interact with each other and with words in dynamic and complex ways. The materiality of the image, the alternation of drawing and painting techniques, the use of the image with or without accompanying words, the use of closed or open panels, the development, repetition, or transformation of the image through and across sequences - these produce a visualization of the post-traumatic state that both corresponds to the rules of the trauma genre and inventively adapts them to the unique possibilities of the form.

For example, when Meurisse represents re-living the traumatic event metaphorically as a plunge off a cliff into deep water in a recurring nightmare of attack, flight and narrow escape, this visualization mobilizes the tension between precise ink drawing and the material indistinction and unpredictability of a graded wash, which literally threatens to absorb the 
character (Meurisse, 2016: 44). When Meurisse is shown behind metal shutters metaphorizing her sense of isolation (see Fig.1.1), the specifics of the chosen visualization quickly develop the illustration of inaccessibility into something more complex. Initially appearing as the shopfront roller grilles of the office off the street in which Meurisse and two colleagues find shelter (17), they return four pages later within an abstract, three-dimensional space (21).

Insert Fig. 1: Meurisse on the day after the attack (Meurisse, 2016: 21).

The nine-panel sequence verbally identifies the shutters as a barrier between Meurisse and her ability to draw, but the specificity of shopfront roller grilles visually complicates the verbally stated permanence of her state ('It's over. I'm through with drawing'). The image evokes mobility, as roller grilles move up and down with scheduled regularity. The image also utilizes the reduction of comics space through stylized abstraction, making it ambiguous as to whether the character is inside or outside (trapped or excluded) in a potentially infinite space of solitude. Given that roller grilles are associated with security, this indeterminacy of inside and outside visually alludes to larger trade-offs between liberty and security relevant to the context of terrorism. The visual implications of this early sequence return more explicitly later, when Meurisse is driven crazy by living under permanent protection with a guard posted outside her building: 'I am imprisoned. My freedom is dead' (45).

The most familiar components of trauma aesthetic can take on a medium-specific life of their own in graphic narrative, especially when the narrative employs the differential appearance of text and image to introduce a dynamic of belatedness, or disarticulation between the two modes. For example, alternations of empty and full speech balloons trace the lost memory and tenuous reconstruction of a conversation with one of the victims on 5 January $(40-41,77)$, as the visual convention of representing speech in comics allows Meurisse to represent the absence of remembered speech, the past occurrence of now forgotten speech, and the awareness of the inability to access a formerly encoded memory. Meurisse's meditation on her survival of the Charlie Hebdo attack is therefore not only saturated with the familiar elements of trauma aesthetic, but also reinvents them in creative, multimodal ways, exploiting the particularities of the comics form.

All this versatility and inventiveness is in the service of a subjective interior account of recovery; even though the traumatic event is an explosion of violence in the public sphere, its aftermath is represented as intensely private. This comics version of trauma aesthetic withdraws not only its protagonist, but also trauma as such from its social and historical 
causes and implications. The recovery process helps the protagonist re-connect with her world, yet this world remains curiously non-public. Art provides an antidote to a violent public sphere, and the concluding scene, which depicts Meurisse pondering her obsession with beauty on a beach, offers the serene transcendence of nature and aesthetic sensibility as a pseudo-social sphere sheltering one from history and politics. This retreat into the subjective may well be a privilege of those who can assume their audience knows and cares about the public events surrounding their trauma. Similarly, while the notion that the laborious production of comics is itself therapeutic is shared by many comics adaptations of trauma aesthetic, this degree of de-politicization is not so common-indeed, the universalization of one's pain through a putatively depoliticized aesthetic is another important form of privilege.

\section{Trauma Contained}

A number of twenty-first century, long-form graphic narratives on traumatic events have adopted this trauma aesthetic less comprehensively or eschewed it altogether. In the remainder of this chapter, I will analyse four such works-ordered according to their diminishing reliance on 'trauma' - and identify a constellation of factors that might account for their increasing avoidance of trauma aesthetic. Déogratias by Jean-Philip Stassen, a Belgian artist living in Rwanda, is a work of historical fiction about genocide in Rwanda (2000/2006); Un printemps à Tchernobyl by Emmanuel Lepage is a documentary work about the aftermath of the Chernobyl nuclear disaster (2012); ${ }^{3}$ Beirut Won't Cry is a graphic memoir by Lebanese artist and musician Mazen Kerbaj, based on the author's internet diary kept during a month-long Israel-Hezbollah conflict (2007/2017); and A.D. New Orleans After the Deluge by American comics journalist Josh Neufeld is about Hurricane Katrina (2009).

Set in a post-genocide present in an unnamed town in Rwanda, Déogratias tells the story of a Hutu teenager — named Déogratias — who gradually assumes the complex role of perpetrator-victim-witness, having been coerced into participating in the genocide. Déogratias descends into hallucinatory fantasies, imagining himself to be one of the scavenging, corpseeating dogs that ran through the streets after the killings. His only remedy for these attacks is alcohol, which relieves him of the intrusive memories and the sense of his own uncontrollable transformation. Unsurprisingly, the work has been frequently read as a trauma narrative

\footnotetext{
${ }^{3}$ As of the time of this writing, an English translation is forthcoming: Springtime in Chernobyl, IDW Publishing, 2019 (translator unnamed).
} 
(Banita, 2013: 60-61; Freedman, 2012: 381-383; Keen, 2011: 139-140) - the protagonist is presented as a severely traumatized young boy and the motifs and structure of the work invoke popular knowledge about trauma. Any reference to trauma is tacit, however, since the work uses colloquial terms for craziness ('[lost] your marbles', 'completely nuts', 'crazy', 'weird' (Stassen, 2006: 5, 7, 19, 55). ${ }^{4}$ At the same time, the narrative structure models traumatic memory; it progresses as a series of involuntary recollections that move increasingly closer to representing the protagonist's involvement in the dehumanization, persecution, and eventual murder of the genocide's victims. Whenever Déogratias' recollections are triggered - whether by certain words or locations - the subsequent intrusion of memories is never explicitly marked, the past appearing unannounced rather than as a staged recollection or testimony.

Recursive narration with delayed interpretation thus becomes a central narrative principle, and until the coding of narrative time through open and closed panel frames is mastered by readers, they share the protagonist's disorientation. In this way readers, like Déogratias himself, perceive sites, objects and characters before fully understanding their meaning. Furthermore, the narrative visually represents the lasting, delayed impact of past experiences as the protagonist's unwilled, total transformation into a street dog shatters his sense of humanity. ${ }^{5}$ If all this makes Déogratias sound deceptively like La Légèreté in its comprehensive adoption of trauma aesthetic, it is important to note that the discourse of trauma is implicit here, and these narrative features shape the work only through the postgenocide storyline. Unlike the deeply subjective, impressionistic, essentially psychological landscape of Meurisse's search for lost 'lightness', the pre-genocide storyline develops the basics of the socio-historical context through strategically chosen supporting characters and informative details (e.g. the colonial history of ethnic classification, agricultural development, the role of radio broadcasts in hate propaganda and genocide, and so on).

As its recursive narrative cycles of pre-genocide and post-genocide storylines move ever closer to a revelation of the withheld traumatic event itself, Déogratias creates an expectation in readers of therapeutic reparation, culminating in a final scene, when Brother Philip - a well-meaning if naïve priest new to Rwanda-asks: 'Where are the others?' (Stassen, 2006: 68). This key testimonial scene allows Brother Philip, the diegetic listener,

\footnotetext{
${ }^{4}$ The French terms in the original are: 'maboul'; 'complètement louf'; 'nous sommes tous meurtris: tu es fou et moi, je suis si fatigué'; 'bizarre' $(7,9,21,57)$.

${ }^{5}$ Michael Chaney has identified the animal as a recurring image 'evocative of traumatic narration' in several works about the Rwandan genocide (2011: 95).
} 
along with the reader-as-witness, to piece together what happened. However, the long-awaited revelation is instantly doubled: the witness's reconstruction of the past (telling the listener) is also attempted murder (killing the listener, Brother Philip, with poison). It transpires that Déogratias has been exterminating the exterminators in an act of retribution (the revenge motive is underlined by the correspondence between the pesticide used as poison and the word 'cockroach' in the language of hate propaganda). The final scene, however, also posits the poison as a metaphor for the transmission of trauma in a lethal chain of witnessing. Poison is materially deposited in the body of the witness, and though this poison is, like trauma, now inaccessible to its carrier, they remain vulnerable to its delayed and potentially lethal effects. Just as nothing can save the protagonist from the irreversible dissolution of the traumatized self, a complete transmission of the knowledge of what happened would annihilate the secondary witness (in this case, the priest). This speaks to one of the most vexed issues of trauma theory: what is the relationship between trauma, secondary witnessing, and its reception mediated by $\operatorname{art}^{6}{ }^{6}$ Déogratias negotiates this by sustaining the sacralisation of trauma as an inexpressible limit experience in the narrative, yet affirming its transmission through the existence of the book, which is after all itself accessible to a broad audience.

If Stassen's Déogratias exemplifies a restricted, structural use of the tropes of trauma, Emmanuel Lepage's account of the Chernobyl disaster exemplifies what I would describe as spectral trauma aesthetic, a curious transposition of trauma as the expected discourse for monstrous events. Lepage and Gildas Chasseboeuf visited Chernobyl in 2008, twenty-two years after the explosion of reactor No. 4. Their trip, a two-month art residency in a village near the Exclusion Zone, was arranged by the activist art organization 'Dessin'Acteurs', whose sympathies are clearly aligned with the anti-nuclear movement. The two were commissioned to produce a collection of travel pictures in aid of the humanitarian association Les enfants de Tchernobyl, which funds children affected by the disaster to take short holidays in France. ${ }^{7}$ Lepage is sent on a mission to testify, to act as secondary witness to catastrophe, and the result-Un printemps à Tchernobyl - is a book-length documentary comic combining travelogue and reportage and chronicling the entire journey, from preparation to return.

\footnotetext{
${ }^{6}$ See, for instance, Dominick LaCapra's discussion of the listener's and secondary witness's role, the dangers of (over)identification and the requirement of "empathic unsettlement" (LaCapra, 1998; 2000: 43-114). See also Hirsch and Spitzer, 2010 and Hoffman, 2010.

${ }^{7}$ This co-authored carnet was produced, sold out and was eventually republished by a press under the title Les fleurs de Tchernobyl: carnet de voyage en terre irradiée, not identical with Lepage's own graphic narrative discussed here.
} 
The opening sections of the book resemble a now paradoxically conventional narrative of trauma defined as a 'category of damage [marking] the limit of conventionalized, assimilable experience' (Ray, 2016: 1). The epigraph is taken from Rainer Maria Rilke's First Duino Elegy (11. 4-7), a locus classicus for the sublime that connects terror, awe, and transcendence in the figure of the terrifying (schrecklich) angel. The extreme abstraction of such colossal annihilation in Rilke's poem clashes abruptly with the microscopic specificity of acute radiation poisoning as documented in the harrowing testimonies collected in Svetlana Alexievich's Chernobyl Prayer (1997) — the book Lepage is reading, in French, on the Warsaw-Kiev train ride in the comic's opening scene (Lepage, 2013a: 3-7). These two preliminary views together frame 'Chernobyl' - ahead of the informative ten-page account of the accident (8-17) — as a case of the traumatic sublime. This expectation also materially shapes the work through the art supplies Lepage brings with him from France: the 'black pencils and inks', the colour he had presumed appropriate for Chernobyl's 'morbid landscapes' before even visiting the site (Lepage, 2013b).

Instead of fulfilling these expectations, however, the narrative turns out to be the documentation of the unexpected abundance of life. Organized information sessions for visitors and informal conversations with locals allow Lepage to gather stories of the disaster and its aftermath, but there is just as much focus on the Exclusion Zone. The zone contains a surprising beauty and natural plenitude; deprived of human habitation, the disaster area has transformed into 'Nature' (a nature preserve reminiscent of a prehistoric wilderness), while its actual nature remains inaccessible to the human senses without the aid of technical equipment. Acts of representation and the limits of perception move centre stage in the recurring drawing excursions that constitute much of the plot. The eerie absence of material signs of contamination is recorded in luminous landscapes, where occasional artefacts, such as a bus stop shelter, prompt imaginary reconstructions of past lives (Lepage, 2013a: 110). 'When I look at the drawing', comments Lepage in an interview, 'I realize that my senses tell me nothing about the real. A disturbing situation, you know it's dangerous, the Geiger counter reminds you, and yet you see nothing, you sense nothing' (Lepage, 2013b). The graphic narrative itself, however, is a far more nuanced exploration of the 'real' under such conditions. The reality of the perceptible is not erased or overwritten; rather, the multimodal narrative is able to overlay this invisible dimension onto the perceptible, prosthetically as it 
were. ${ }^{8}$ Dosimeter readings are materially transferred and incorporated into the drawings, as are the persistent beeps of the machine (Lepage, 2013a: 111). The drawing and the text together realize this tension, creating a gap that keeps the artist oscillating between spells of anxiety and calm. This decidedly counter-dramatic structure of the work deflates the obligatory drama of the original traumatic event, despite the fact that the monumentalization of this trauma was the artist-witness's original task.

Fig. 2: (Lepage, 2013a: 113).

Yet trauma construed as an inaccessible and inexpressible experience is not entirely absent from this text, but rather transferred to the landscape, itself a traumatized non-human life form. The evidence the witness seeks is embedded into the landscape at a level inaccessible to conscious communication and narration. In a fellow visitor's project, dental Xray film is buried in the ground for 75 hours; when retrieved, it shows a dark opaque area- $\mathrm{s}$ Lepage comments, 'earth has spoken' (Lepage, 2013a: 107, 114). Yet the very artifice, indirection and technological mediation needed to visualize this 'speech' reinforces the difference between the verbal testimonies of local survivors and the silent, lingering emissions-as-speech. By being physically present in the toxic landscape, Lepage is inescapably 'listening' to both: while trying to record the faces of Chernobyl, his witnessing also takes place at a biophysical level in the Zone. Brought into this field of danger, it is the artist's body that records the real in its fullest sense, along with his drawing's 'body' that materially suffers the effect of radiation, though unregistered by his senses. Lepage's depicted body represents this invisible witnessing of trauma through the ritualized protocols of necessary precautions: putting on the mask, shoe covers, and gloves, going through the exit screening procedure, or, for instance, when he drops his crayon and remembers he must not pick it up (2013a: 109). As the comic evidences, it is the specific multimodality of graphic narrative and the embodied nature of drawing that allow for this spectral trauma aesthetic.

\section{Counter-Discourses}

\footnotetext{
${ }^{8}$ This is related to discussions of the 'spectral' in trauma and photography (see Baer, 2000), but also departs from them — these are after all drawings, not photographs (Orbán, 2015).
} 
The two final works I explore entirely eschew the trauma aesthetic, even as they depict ostensibly traumatic events and experiences. They respond to a catastrophic event and represent moments of terror and loss, yet do not turn these into a narrative of trauma, despite the occasional assumption that the works should do so (see Coby, 2015: 113). This arises from two factors related to the works' conditions of production. For Kerbaj's Beirut Won't Cry, it is the absence of retrospective reconstruction and the disregard for symbolic difficulties of articulation that resist trauma aesthetic. The temporal immediacy enforced by the diary genre works to this effect: Beirut Won't Cry began as a blog with serial posts published almost coterminously with the events it depicts (and it was minimally revised for the book editions). Its fragmentation is therefore more closely tied to format and serialization than to devices of narrative difficulty in trauma aesthetic. In the second case, the heterogeneity and multiplicity in Josh Neufeld's A.D. 'disperses crisis witnessing across an ensemble of subject positions', hybrid genres and multiple sites of witnessing, of which the published book is only one manifestation (Smith, 2011: 69-70). In these ways, both works avoid the apparent affinity between trauma aesthetic and fully formed retrospective long-form comic narratives with a single protagonist.

Beirut Won't Cry, the visual diary by Lebanese comics artist and musician Mazen Kerbaj (2007, 2017), covers a month-long military conflict that left over a thousand people dead. The daily blog entries (sometimes several a day) were authored nearly contemporaneously with the events and with no reliance on formalized trauma tropes. Instead of the transcendent and often sacralised 'unsayability' of traumatic experience, expressive difficulties are a result of wartime conditions - electricity blackouts, long upload times, shaky car rides, are all realtime obstacles to creating and sharing drawings. 'I have 31 minutes left on my laptop battery. No, in fact, 30 minutes. Just enough time to write this post, but no time to upload today's drawings (and some of yesterday's). [...] It is quite funny to write on a laptop connected to the world with a candle next to the keyboard to see the letters' (Kerbaj, 2017: July 31, 2006). ${ }^{9}$ Kerbaj grapples with medium-specific modes of expression rather than metaphysical challenges to expressibility: 'how can I show sound in a drawing?' The diary entries are composed on pages of a notepad, more often than not contained in single-panel pages, and in their quick, agitated style they visually capture the fragile or conflicted mental state of the author as he records an immediate present under constant threat of violent

\footnotetext{
${ }^{9}$ The book is unpaginated and only provides date references in the published diary. These dates are indicated here to guide readers, as far as possible, to the correct pages.
} 
interruption. Yet these small slices of time do not consolidate into traumatic shock or collapse. In fact, it is the normalization of an incremental, scary, infuriating and depressing material reality - the fatigue of coping rather than any (quasi-)transcendental break - that dominates: 'how hard it is to get used to being used to living in war' (August 9, 2006).

The diary represents personal fear in a highly politicized socio-historical field of vulnerability and resistance that posits the question of expression and agency as socially contested, and highlighting the framings of war that produce a 'differential distribution of precariousness and grievability' (Butler, 2009: 31). There is after all a drastic disparity of attention registered in Kerbaj's craving for media access and Meurisse's mediaphobia as she is hounded by reporters. The 'real news' from Kerbaj's brain enters a complex mediascape, in which 'the space of appearance for the political' depends on material conditions such as infrastructure, including "particular ways that the public sphere is structured to keep such actions from appearing' (Butler, 2016:14). In this respect, Stassen occupies an intermediate position: he does have to fuse the subjective drama with an informative account, as he cannot depend on his audience's familiarity with the social context of the Rwandan genocide. But the global consciousness of that event still lessens the burden of achieving visibility and attention, and the retrospective production of the account eliminates practical challenges to communication. Though the page of the graphic diary bears a visible, material imprint of circumstances, the turmoil of the location of writing, and of the mental or physical state of the artist, all generates expressive material, rather than failing in moments of inexpressibilityeven though the fate of that expression remains precarious.

There is a tension here between the general temporal disposition of the diary as a nonretrospective 'contact with a vast future', including and exceeding the writer's future self (Lejeune 2009: 334), and the practical risk of no future for either writer or diary. ${ }^{10}$ This makes the diary a gesture of hope through the very mundanity of practice; at the same time, the practice of near-instantaneous processing with the help of portable tools and on-site representations counteracts dissociation as the core of trauma aesthetic. In fact, daily drawing establishes a nexus between emotional and mental intimacy and public communication, thwarting the monumentalization of trauma. Instead of post-traumatic compulsion, repetition

\footnotetext{
${ }^{10}$ For an extensive analysis of the temporality of the war diary and its implications for haptic visuality, see Orbán 2018: 244-250.
} 
appears here in the form of practice, where therapeutic art is a means of sustaining agency through practice rather than a means of transcending lived experience. ${ }^{11}$

Meanwhile, Josh Neufeld's A.D. uses the composite experience of seven people to document the events of Hurricane Katrina. Accordingly, individual psychology is framed by a long view of human events, the symbolic scale of catastrophe (announced in the Biblical reference of the title and the perspective of the first panel showing Earth from space), and a social analysis of human action and agency. Comics journalism frequently includes representations of the reporter and the journalistic process; relegating this to the afterword and avoiding narration altogether in a dialogue-only central narrative, Neufeld de-emphasizes his own integrating journalistic subjectivity to effectively present his extensive research and interviews as a representative, composite experience of Katrina. The images are presented in monochromatic palettes combined with black and white, colour-coded by sections, dates or parts of the day (in shades identified in the very last panel as the colours of the Mardi Gras flag into which they combine). This colour-coding also emphasizes the synchronicity of disparate experiences existing at the intersection of subjective lived experiences and a standardized regime of calendar date and time. Across the chapters there are several doublepage spreads that address the enormity of overwhelming events, such as the onset of the storm and the flood (16-17, 24-25), Denise barely surviving the worst of the storm in her home (6771), Leo realizing his comics collection has been wiped out (116-117), and the futile fight for water to save a dehydrated baby or the fear of being trapped and left to die (140-141, 150151). However, these narrative contexts relativize each other; for example, once juxtaposed, the loss of a comic book collection to water and the loss of a baby to a lack of water, simply explode any abstract sense of loss removed from a nuanced social context, in which unequal access to houseing, for instance, is not metaphorized into a sense of dislocation (Davies 2019: $7-8,12)$. This narrative strategy allows A.D. to resist 'processes of identification with suffering as replacements for more traditional modes of political allegiance formation' (Radstone and Schwarz, 2008: 34).

\footnotetext{
${ }^{11}$ Kerbaj's affinity to the series as a product of daily routine is not limited to the serial publication of daily newspaper comic strips (collected in Cette Histoire Ce Passe, for example). After his relocation to Berlin in 2016, his recent self-portrait series Learning Deutsch (2018) applies it to the effects of exile rather than war. Created in a single sketchbook and serially published on Instagram, the work is an excuse to experiment and play, while also processing the reshaping of the dislocated subject through the discipline of assimilating the words of a foreign language into the self day by day (https://www.instagram.com/mazenkerbaj/).
} 
Although some critics have commended the book for its apparent adherence to a trauma aesthetic (Reed, 2009; Dyer Hoefer, 2012), this unduly amplifies the narrative emphasis on the difficulties of remembering or understanding the traumatic experience of Katrina victims. The discrepancy between the book's avoidance of trauma as a frame and the use of this frame in its reception seems to mark two contradictory approaches to trauma aesthetic: it is both wary of trauma aesthetic's privatization of pain, yet receptive to its seal of recognition. Even though the attention to social causes and public accountability could, in principle, be amplified by invoking the interviewees' traumatization, the author seems to have avoided it to keep the collective accounts embedded in a social sphere rather than the subjective interior landscape emphasized in Meurisse's book. The fact that it nevertheless returns in the book's reception reflects the current importance of this framework for the recognition of suffering.

As these two final examples illustrate, the near immediacy of representation or the dispersal of subjectivities may be significant factors in eschewing the tropes of trauma. Yet, treating these representational choices simply as circumstantial narrative strategies would downplay the geopolitically inflected cultural power of the discourse of trauma - that is, the extent to which the adoption of trauma aesthetic may have implications for the recognition of human suffering, and furthermore its possible consolidation of hierarchies of pain. If the tropes of trauma signal a recognized, privileged suffering, adopting trauma aesthetic in graphic narrative may be attractive partly because a book's inclusion in the canon of trauma narratives confers exactly this privileged recognition. Yet the range of examples discussed in this chapter shows that the comics form also offers a wealth of possibilities for innovatively adapting and resisting the conventionalization of the tropes of trauma.

\section{Works Cited}

Alexievich, Svetlana. 2016. Chernobyl prayer: a chronicle of the future. Translated by Anna Gunin and A. L. Tait. London: Penguin Classics.

Baer, Ulrich. 2000. Spectral Evidence: The Photography of Trauma. Cambridge: MIT.

Banita, Giorgiana. 2013. "Cosmopolitan Suspicion: Comics Journalism and Graphic Silence." In Transnational Perspectives in Graphic Narratives: Comics at the Crossroads. Edited by Shane Denson, Christina Meyer, and Daniel Stein. London: Bloomsbury. 49-66.

Beaty, Bart. 2018. "Don't Pray for Paris: Drawing in Post-Charlie Hebdo Graphic Novels." ImageTexT, vol 9, no. 2, 2017. n. pag. Dept of English, University of Florida. 19 January 2018.

Butler, Judith. 2016. "Rethinking Vulnerability and Resistance." In Vulnerability in Resistance. Edited by Judith Butler, Zeynep Gambetti, and Leticia Sabsay. Durham: Duke University Press. 12-27. 
Caruth, Cathy. 1996. "Trauma and Experience." In Trauma: Explorations in Memory. Baltimore: Johns Hopkins Univ. Press.

Chambers, Ross. 2002. "Orphaned memories, foster-writing, phantom pain: the fragments affair". In Extremities: Trauma, Testimony, and Community. Edited by Nancy K. Miller and Jason D. Tougaw. Urbana: University of Illinois Press. 92-111.

Chaney, Michael. 2011. In Graphic subjects: critical essays on autobiography and graphic novels. Edited by Michael Chaney. Madison, Wisconsin: University of Wisconsin Press. 93-100.

Chasseboeuf, Gildas, and Emmanuel Lepage. 2012. Les fleurs de Tchernobyl: carnet de voyage en terre irradiée. Antony: La Boîte à bulles.

Chute, Hillary. 2017. Why Comics? New York: Harper.

Coby, Jim. "'-it's pretty easy to forget what it's like to be a have-not'. Envisioning and Experiencing Trauma in Josh Neufeld's A.D.: New Orleans After the Deluge."South Central Review, $32: 3,110-123$.

Craps, Stef. 2014. "Beyond Eurocentrism: Trauma Theory in the Global Age." In The future of trauma theory contemporary literary criticism. Edited by Gert Buelens, Sam Durrant, and Robert Eaglestone. New York: Routledge. 45-61.

Davies, Dominic. 2019. Graphic Katrina: Disaster Capitalism, Tourism Gentrification and the Affect Economy in Josh Neufeld's A.D.: New Orleans after the Deluge (2009).

Journal of Graphic Novels and Comics. https://doi.org/

$10.1080 / 21504857.2019 .1575256$

Dyer Hoefer, Anthony. 2012. "A Re-Vision of the Record. The Demands of Reading Josh Neufeld's A.D.: New Orleans After the Deluge." In Comics and the U.S. South. Edited by Brannon Costello and Qiana J. Whitted. Jackson: Univ. Press of Mississippi. 293324.

Freedman, Ariela. 2012. "Sorting through My Grief and Putting It into Boxes": Comics and Pain." In Knowledge and Pain. Edited by Esther Cohen, Leona Toker, Manuela Consonni, and Otniel E. Dror. Amsterdam: Rodopi. 381-399.

Gibbs, Alan. 2014. "The problem is, I'm not sure I believe in the thunderclap of trauma": aesthetics of trauma in contemporary American literature.' In The edges of trauma: Explorations in visual art and literature, edited by Tamás Bényei \& Alexandra Stara, 148-168. Newcastle upon Tyne: Cambridge Scholars Publishing.

Groensteen, Thierry. 2017. "Biographies of Famous Painters in Comics: What Becomes of the Paintings?" ImageTexT, vol 9, no. 2, 2017, n. pag. Dept of English, University of Florida. http://imagetext.english.ufl.edu/archives/v9_2/groensteen/

Hirsch, Marianne and Leo Spitzer, 2010. 'The Witness in the Archive: Holocaust Studies/Memory Studies.' In In Susannah Radstone and Bill Schwartz, eds. Memory: Histories, theories, debates. New York: Fordham University Press. 390-405.

Hoffman, Eva, 2010. 'The Long Afterlife of Loss.' In Susannah Radstone and Bill Schwartz, eds. Memory: Histories, theories, debates. New York: Fordham University Press. 406415.

Kansteiner, Wulf. 2006. "Genealogy of a category mistake: a critical intellectual history of the cultural trauma metaphor," Rethinking History, 8:2, 193-221.

Keen, Suzanne. 2011. "Fast Tracks to Narrative Empathy. Anthropomorphism and Dehumanization in Graphic Narratives." SubStance 40.1. 135-155.

Kerbaj, Mazen. 2007. Beyrouth, juillet-août 2006. Paris: L'Association.

. 2011. Cette Histoire Ce Passe. France-Lebanon: Tamyras. 
2017. Beirut Won't Cry. Lebanon's July War: A Visual Diary. Seattle: Fantagraphics Underground.

Klüger, Ruth. 1998. "Kitsch ist immer plausibel. Was man aus den erfundenen Erinnerungen des Binjamin Wilkomirski lernen kann". In: Süddeutsche Zeitung Nr. 225, 30. September 1998, S. 17.

LaCapra, Dominick, 1998. 'Lanzmann's Shoah: "Here There Is No Why"'. In History and Memory After Auschwitz. Cornell University Press. 95-138.

, 2000. Writing History, Writing Trauma. Johns Hopkins University Press.

Lepage, Emmanuel. 2013a. Un printemps à Tchernobyl. [Paris]: Futuropolis.

Lejeune, P. (2009), On Diary, eds J. Popkin and K. Durnin, Hawaii: University of Hawaii Press.

-. 2013b. Interview. Revue Sortir du nucléaire $\mathrm{n}^{\circ} 57$. http://www.sortirdunucleaire.org/Un-printemps-a-Tchernobyl.

Maechler, Stefan. 2001. The Wilkomirski Affair: A Study in Biographical Truth, translated by John E. Woods. New York: Random House.

McNally, R. J. 2003. Remembering Trauma. Cambridge,MA:Belknap Press, Harvard University Press.

Meurisse, Catherine. 2016a. La légèreté. Dargaud. Preface by P. Lançon.

. 2016b. The Lightness. Harper's. December 2016. 55-57.

Neufeld, Josh. A.D.: New Orleans after the Deluge. New York: Pantheon, 2009.

Orbán, Katalin. 2015. 'Mediating distant violence: reports on non-photographic reporting in The Fixer and The Photographer'. Journal of Graphic Novels and Comics, 6:2, 122137.

Orbán, Katalin. 2018. "Closer Than They Seem: Graphic Narrative and the Senses." in Zara Dinnen and Robyn Warhol (eds.) The Edinburgh Companion to Contemporary Narrative Theories, (Edinburgh: Edinburgh University Press, 2018), 239-255.

Proust, Marcel. Swann's Way. Trans. Lydia Davis. New York: Penguin, 2004.

Radstone, Susannah. 2008. Memory Studies, 1(1): 31-39. . 2010. Cache: or what the past hides. Continuum : journal of media and cultural studies, vol. 24, no. 1, pp. 17-29.

Radstone, Susannah and Bill Schwarz, 2010. Memory: Histories, theories, debates. New York: Fordham University Press.

Ray, Gene. 2016. Terror and the sublime in art and critical theory: from Auschwitz to Hiroshima to September 11. New York: Palgrave Macmillan.

Reed, John. 2009. Review of 'A.D.: New Orleans After the Deluge' by Josh Neufeld. Http:/Www.Latimes.Com/Books/La-Ca-Josh-Neufeld23-2009aug23Story.Html

Smith, Sidonie. 2011. "Human rights and comics: Autobiographical avatars, crisis witnessing, and transnational rescue networks." In Graphic subjects: critical essays on autobiography and graphic novels. Edited by Michael Chaney. Madison, Wisconsin: University of Wisconsin Press. 61-72.

Stassen, Jean-Phillipe. 2000. Déogratias. Marcinelle: Dupuis.

- 2006. Deogratias: A Tale of Rwanda. Translated by Alexis Siegel. New York: First Second Press.

Suleiman, Susan Rubin. 2000. "Problems of Memory and Factuality in Recent Holocaust Memoirs: Wilkomirski/Wiesel. Poetics Today. 21 (3): 543-559.

Vice, Sue. 2002 Binjamin Wilkomirski's Fragments and Holocaust Envy: 'Why Wasn't I There, Too?'. Immigrants \& Minorities, 21:1-2, 249-268. 